\title{
Peripheral chemoresponses of infants measured by a minimally invasive method utilizing two-breath alternations in $\mathrm{A}, \mathrm{O}_{2}$
}

\author{
D.A. Thomas*, K. Poole*, E.K. McArdle*, C.S. Beardsmore*, \\ P.C. Goodenough*, J. Thompson**, H. Simpson*
}

Peripheral chemoresponses of infants measured by a minimally invasive method utilizing two-breath alternations in $\mathrm{F}_{\mathrm{I}} \mathrm{O}_{2}$. D.A. Thomas, K. Poole, E.K. McArdle, C.S. Beardsmore, P.C. Goodenough, J. Thompson, H. Simpson. CERS Journals Ltd 1996. ABSTRACT: The aim of this study was to develop a minimally invasive and reliable method for measuring peripheral chemoresponsiveness to oxygen in infants, and to establish baseline data from normal infants at 12 weeks of age.

Two-breath alternations in fractional inspired oxygen $\left(\mathrm{F}_{\mathrm{I}}, \mathrm{O}_{2}\right)$, switching between 0.42 to 0.00 were given for 2 min periods via a face mask (held close to the face but without contact) to 18 healthy infants during quiet sleep. End-tidal oxygen concentrations alternated between 21 and $11 \%$. Instantaneous minute ventilation $\left(V^{\prime} \mathrm{E}\right)$ and its components tidal volume $\left(V_{T}\right)$, respiratory frequency $\left(f_{R}\right)$ inspiratory and expiratory times $\left(t_{\mathrm{I}}\right.$ and $\left.t_{\mathrm{E}}\right)$, inspiratory flow $\left(V_{\mathrm{T}} / t_{\mathrm{I}}\right)$, and inspiratory duty cycle $\left(t_{\mathrm{I}} / t_{\mathrm{t}}\right)$ were measured by respiratory inductance plethysmography. Two-breath alternations in each of the ventilatory components were matched with the corresponding alternating end-tidal oxygen record and compared with contiguous pre- and post-test data obtained in control periods of air breathing.

Alternations in all ventilatory components except $f_{\mathrm{R}}$ changed significantly during $F_{1}, O_{2}$ alternations; $V_{\mathrm{T}} 26 \%, t_{\mathrm{E}}-8 \%, V_{\mathrm{T}} / t_{\mathrm{I}} 18 \%, t_{\mathrm{I}} / t_{\text {tot }} 11 \%$ and $V^{\prime} \mathrm{E} 28 \%$ of baseline values. Within and between infant variances are reported for the individual components of ventilation. Differences among infants were best detected by alternations in $V^{\prime} \mathrm{E}$; within infant variance 76, between infant variance 171 .

We conclude that the test described is a safe, reliable and relatively easily applied method of measuring peripheral chemoresponsiveness, which is suitable for clinical application in infancy.

Eur Respir J., 1996, 9, 1261-1268.
Depts of *Child Health and **Ophthalmology, University of Leicester, Clinical Sciences Building, Leicester Royal Infirmary, Leicester, UK

\section{Correspondence: D. Thomas}

Dept of Child Health

Queens Medical Centre

Nottingham NG7 2UH

UK

Keywords: Carotid body

chemoreceptors

infant physiology

respiratory control

Received: March 221995

Accepted after revision January 311996

Supported by a grant from the Foundation for the Study of Infant Deaths (project 155).
Peripheral chemoresponses to oxygen are conventionally assessed by measuring the ventilatory response to changes in inspired oxygen. There are various established methods. Those utilizing prolonged hypoxia [1] or hyperoxia [2] are limited by the interaction of oxygen and carbon dioxide chemoreflexes and ethical concerns about the degree and duration of hypoxia. Transient hyperoxic methods measure the ventilatory response to brief inhibition of carotid body activity [3, 4]. Transient hypoxic methods adapted for use in infancy [5] have utilized alternate breaths of hypoxic and normoxic gases, thereby highlighting the dynamic activity of peripheral chemoreceptors. The stimulus/response characteristics that are both optimal and safe have not been defined.

Studies in infants have established that peripheral chemoresponsiveness is largely genetically determined [6], and that responses at birth are small [3] but increase thereafter and remain stable between 1-3 months [4, 7]. Weaker peripheral chemoresponses have been reported in infants with resolving bronchopulmonary dysplasia, a group at increased risk for sudden infant death [8].

Measurements of ventilation have usually been made with the infant asleep, using a pneumotachograph and an airtight face mask. This method is time-consuming, often disturbs the infant and may induce changes in the respiratory pattern [9]. It is, therefore, not readily applicable to studies of large numbers of infants

The aims of the present study were: 1) to develop a safe and minimally invasive test of peripheral chemoresponsiveness suitable for clinical applications involving large numbers of infants in our laboratory; and 2) to establish baseline data on healthy infants aged 12 weeks. Alternating breath tests seemed most promising in this regard. These have stemmed from the suggestion that periodic variations in blood gas tension are caused by the breathing cycle [10], and from reported variations in peripheral chemoreceptor discharges linked to breathing cycles [11]. Subsequent studies in animals have established: that peripheral chemoreceptors respond to induced changes in arterial carbon dioxide tension $\left(\mathrm{Pa}_{\mathrm{a}} \mathrm{CO}_{2}\right)$ and arterial oxygen tension $\left(\mathrm{Pa}_{\mathrm{a}} \mathrm{O}_{2}\right)$ [12, 13]; that responses to changes in oxygen tension are carotid body dependent [14]; and that exposure to chronic hypoxia may weaken the response [15]. WiLliams et al. [5] (1991) reported small changes in ventilation in infants in response to an alternating inspiratory oxygen fraction $\left(\mathrm{F}_{\mathrm{I}, \mathrm{O}_{2}}\right)$ of 0.21 
and 0.16 (breath-to-breath) delivered by nasal cannulae. The end-tidal oxygen concentrations achieved in response to the alternating stimulus were not reported.

\section{Subjects and methods}

An a priori requirement was to avoid, as far as possible, the use of apparatus that touched the infant's face. Pilot studies were carried out in four infants to mimic the stimulus applied by WiLliams et al. [5] (1991). Alternating $\mathrm{F}_{\mathrm{I}, \mathrm{O}_{2}}(0.21$ and 0.16$)$ were delivered via a face mask (Rusch, size 3 ) held close to but not touching the mouth and nose (approximately $5 \mathrm{~mm}$ ), with a fresh gas flow of $120 \mathrm{~mL} \cdot \mathrm{s}^{-1}$. This resulted in changes in end-tidal oxygen concentration of approximately $1 \%$, measured at the nares by mass spectrometry, and no consistent changes in respiratory patterns when compared with immediate pre- and post-test control periods breathing air were observed. We then experimented with a range of alternating hypoxic/hyperoxic inspired gas mixtures in an attempt to increase ventilatory responses and simultaneously maintain a mean end-tidal oxygen concentration comparable to that found whilst breathing air.

The largest possible alternation in inspired oxygen concentration, between $100 \%$ and $0 \%$, was rejected as the net effect would have been a markedly hyperoxic stimulus leading to a profound decrease in ventilation, or even apnoea [3]. An alternating stimulus of 42 and $0 \% \mathrm{O}_{2}$ was finally chosen on the basis of theoretical modelling and preliminary trials in adult volunteers. Given a theoretical tidal volume $(V \mathrm{~T})$ of $7 \mathrm{~mL} \cdot \mathrm{kg}^{-1}$, a dead space of 2 $\mathrm{mL} \cdot \mathrm{kg}^{-1}$ and functional residual capacity (FRC) of 30 $\mathrm{mL} \cdot \mathrm{kg}^{-1}$, we modelled the effects of these alternations in $F_{\mathrm{I}, \mathrm{O}_{2}}$ on corresponding end-tidal oxygen concentration. We predicted that single-breath alternations would give end-tidal oxygen concentrations of 19 and $12 \%$, and for the second of two-breath alternations the corresponding values would be 21 and $9 \%$.

In adult volunteers, two of the authors (EKMcA and DAT), the mean (SD) end-tidal oxygen concentrations during three runs each of the two-breath alternating test were $22(1) \%$ and $11(1) \%$, respectively, using a face mask $<5 \mathrm{~mm}$ from the face, a gas flow of $300 \mathrm{~mL} \cdot \mathrm{s}^{-1}$ and endtidal sampling at the nares. There were no subjective sensations or reported adverse effects and no changes in simultaneously measured arterial oxygen saturation $\left(\mathrm{Sa}, \mathrm{O}_{2}\right)$ or electrocardiographic activity (ECG). We therefore proceeded to study normal infants using a two-breath alternating method (breath $142 \% \mathrm{O}_{2}$, breath $242 \% \mathrm{O}_{2}$, breath $30 \% \mathrm{O}_{2}$, breath $40 \% \mathrm{O}_{2}$, and so on). This produced larger alternations in end-tidal oxygen concentration and gave more consistent ventilatory responses than single-breath alternations of the same inspired gases.

\section{Subjects}

Infants were recruited initially by means of posters and leaflets on the postnatal wards at Leicester Royal Infirmary and by local newspaper articles and television news programmes. Parents who responded were given a detailed verbal explanation of the study, including the precise nature of the inspired gases, and all the parameters monitored during the tests, including oxygen saturation. The infants volunteered were considered for final selection. Uncomplicated pregnancy, normal delivery at term, absence of neonatal problems and apparent good health at the time of tests were the essential entry criteria. The Leicestershire Health Authority Ethics Committee approved the study, at first provisionally and then finally following review of the transcutaneous oxygen saturation data obtained during studies in the first six infants.

The final group comprised 18 infants, 9 girls and 9 boys, of mean (SD) gestational age 40.5 (0.7) weeks and birthweight $3.5(0.4) \mathrm{kg}$. One infant was the sibling of a sudden infant death syndrome (SIDS) victim. One or both parents of five infants smoked. The infants were studied at a mean (SD) postnatal age 85 (15) days, weight $5.9(0.8) \mathrm{kg}$ and length $60(2) \mathrm{cm}$. All were symptomfree and not on medication. Their habitual sleeping positions were adopted, 17 slept supine and one prone.

\section{Procedure}

Infants were studied between 6 p.m. and 6 a.m. in an air-conditioned sleep laboratory. On arrival, a questionnaire about relevant medical and social details was completed. Infants were then prepared for study, fed and allowed to fall asleep naturally. Thereafter, they were fed on demand.

Electroencephalogram (EEG) (C3-A2, O1-A2), electrooculogram (EOG) and a digastric electromyogram (EMG), electrocardiogram (ECG) standard lead II, oxygen saturation measured by pulse oximeter (Ohmeda Biox 3700a; BOC, Hatfield, UK) with a "Flex II" probe across the lateral aspect of the left foot, and rectal temperature measured $5 \mathrm{~cm}$ from the anal margin (Model $\mathrm{C}$ electronic thermometer; Edale Instruments, Cambridge, UK) were all recorded utilizing a computerized polygraph (CNS Inc., Minneapolis, USA). The EEG, EOG and EMG were utilized for sleep staging. Thoracic and abdominal belts were worn at the level of the nipples and umbilicus, respectively, for respiratory inductance plethysmography (RIP) (Model 150; Studley Data Systems, Oxford, UK) and the signal recorded by a BBC Master series microcomputer. Respired gases were monitored continuously by mass spectrometer (Airspec 2000; Biggin Hill, Kent, UK) via a $1.5 \mathrm{~m}$ length capillary line taped carefully within the nares sampling at a rate of $14.7 \mathrm{~mL} \cdot \mathrm{min}^{-1}$ (sampling time $290 \mathrm{~ms}$ ). The oxygen and carbon dioxide concentration signals were recorded on a chart recorder (Gould ES2000; Gould Inc., Cleveland, USA) at a paper speed of $10 \mathrm{~mm} \cdot \mathrm{s}^{-1}$ during tests.

Sleep state was monitored continuously both by observational and electrophysiological criteria [16]. At the onset of quiet sleep, respiration was monitored by RIP with the thoracic and abdominal channels at equal gain. The proportionality constant for the two channels was computed by software providing a qualitative diagnostic calibration [17]. The amplitude of the RIP sum signal (thoracic and abdominal) was then proportional to tidal volume and provided a measure of ventilation in arbitrary units. Precise volumetric calibrations were not made.

Each run comprised three consecutive 2 min phases: an initial control period breathing air; the test period of two-breath alternations between $42 \%$ oxygen in nitrogen and $100 \%$ nitrogen; and a final control period. All 


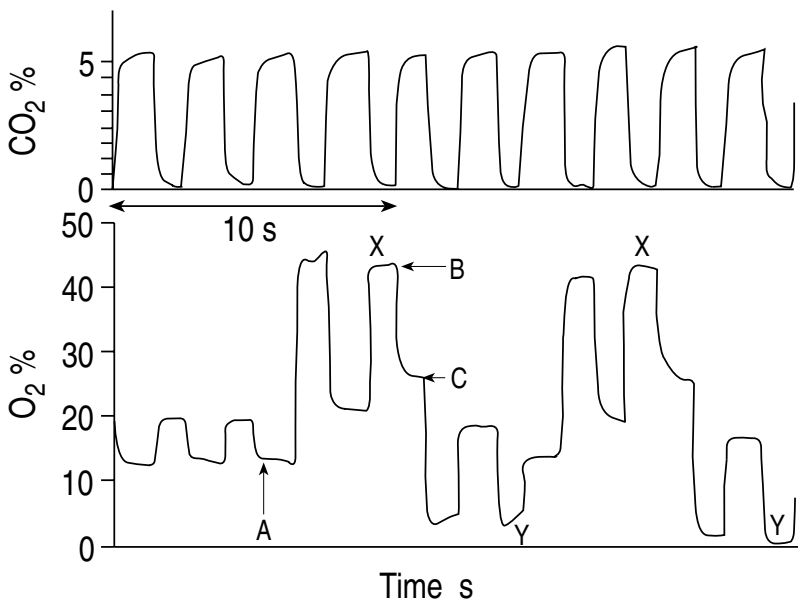

Fig. 1. - Tracing of the oxygen and carbon dioxide concentrations during a test monitored by mass spectrometer sampling at the nares. At point (A) the infant is switched from continuous air-breathing to two-breath alternations in inspiratory oxygen fraction $\left(F_{\mathrm{I}}, \mathrm{O}_{2}\right)$. Inspired (B) and end-tidal (C) gas concentrations were measured during tests, separately, for all second breaths of high (X) and low (Y) oxygen concentration. The mean end-tidal gas concentrations were computed both for the baseline and test periods, and separately for second breaths of high and low oxygen concentration, respectively.

the inspired gases (medical air, $42 \%$ oxygen in nitrogen and $100 \%$ nitrogen) were delivered at $120 \mathrm{~mL} \cdot \mathrm{s}^{-1}$ via microcomputer controlled solenoid valves and a clear silicone rubber face mask (Rusch size 3) handheld as close to the infant's face as possible without contact. Figure 1 is a tracing of the oxygen and carbon dioxide concentrations measured at the nares at the beginning of a test period, indicating the switch from continuous air-breathing to two-breath alternations in $F_{1}, \mathrm{O}_{2}$. The starting order of alternations, 0.00 or $0.42 F_{\mathrm{I}} \mathrm{O}_{2}$, was randomly assigned. Switching of gases early in expiration ensured flushing of the face mask prior to the next inspiration. Occasionally infants moved at the beginning of a run but provided there were no truncal movements, that they settled within $15 \mathrm{~s}$ and that the EEG continued to be dominated by slow waves the run was continued. A BBC Master series microcomputer with a maths coprocessor and custom written software [5] controlled the solenoid valves, and analysed and stored the inductance plethysmograph signals for use in all subsequent analyses. Runs were repeated, whenever possible, during periods of quiet sleep.

\section{Analyses}

\section{Gas concentrations}

For the initial baseline period, the mean inspired oxygen concentration and the mean end-tidal oxygen and carbon dioxide concentrations of the final 10 breaths were computed. For the test period, the mean values for the second of each breath pair were calculated both separately for high and low oxygen concentrations and collectively for all second breaths (fig. 1).

\section{Plethysmograph signal}

Each breath was identified from the sum respiratory inductance plethysmograph signal by a peak picking routine.
Inspiratory and expiratory times ( $t \mathrm{I}$ and $t \mathrm{E}$ ) and tidal volumes $(V \mathrm{~T}, \mathrm{I}$ and $V \mathrm{~T}, \mathrm{E})$ were measured. The following parameters were then computed on a breath-by-breath basis: tidal volume $\left(V_{\mathrm{T}}\right)$, respiratory rate $\left(f_{\mathrm{R}}\right)$, inspiratory duty cycle $(t \mathrm{I} / t$ tot $)$, instantaneous inspiratory flow $\left(V_{\mathrm{T}} / t \mathrm{I}\right)$ and instantaneous minute ventilation $\left(V^{\prime} \mathrm{E}\right)$. Since precise volumetric calibrations were not undertaken, measurements of volume were not strictly quantitative, but proportional changes in volume could be accurately determined.

The ventilatory patterns corresponding to the control and test periods within each run selected for analysis were computed as the mean, standard deviation and standard error for each of the breathing parameters recorded. Records were inspected for the longest periods of uninterrupted breathing of at least 20 breaths in the three phases of each run. Apnoeas (isolated expiratory pauses longer than the average expiratory time by more than two standard deviations), hypopnoeas (isolated breaths with a tidal volume smaller than the mean tidal volume by more than two standard deviations), and sighs (isolated breaths with a tidal volume larger than the mean tidal volume by more than two standard deviations), were excluded from the analysis.

The second breath of consecutive low and high oxygen concentration breath couplets were paired (fig. 1) for each test period. Similarly, alternate breaths were paired for the baseline periods. For each breath pair, the change in each of the above parameters was computed and expressed as a percentage of the average of the two breaths, the percentage alternation, e.g.

$$
\% \text { alternation } V_{\mathrm{T}}=\frac{2 \times\left(V_{\mathrm{T}} \text { breath } 1-V_{\mathrm{T}} \text { breath } 2\right)}{\left(V_{\mathrm{T}} \text { breath } 1+V_{\mathrm{T}} \text { breath } 2\right)} \times 100
$$

The mean of these percentage alternations for each control and test period within a run was then computed. Alternations in $V_{\mathrm{T}}$ during test periods were taken to be positive in sign.

A brief but variable lag between the onset of alternations in $F_{1}, \mathrm{O}_{2}$ and resulting changes in ventilation was a consistent finding. This lag was eliminated in every case by excluding the first four breath pairs in each test period from further analysis.

As an index of the consistency of the respiratory responses, the percentage alternations were also plotted cumulatively for baseline and test periods as in figure 2, and the corresponding correlation coefficients computed.

\section{Sleep scoring}

The polygraphic record of each infant was scored by one observer (DAT) blind to the timing of the alternating $F \mathrm{I}, \mathrm{O}_{2}$ tests, utilizing Anders' criteria [16]. Only those tests recorded during quiet sleep are reported.

\section{Statistical methods}

The measurements were analysed using the random effects model analysis of variance (ANOVA), which enabled the estimation of variation within and between infants [18]. Quoted standard errors make allowance for both of the sources of variation. Characteristics of the 


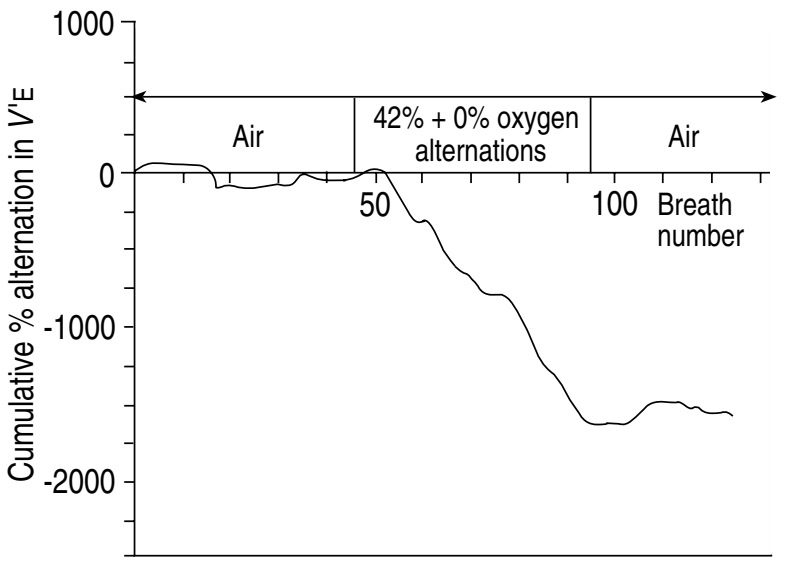

Fig. 2. - Cumulative plot of percentage alternation in instantaneous minute ventilation $\left(V E^{\prime}\right)$ for consecutive breath pairs in a single trial. The two baseline air-breathing periods, during which no consistent alternation is seen, sandwich and run continuously with the period of two-breath alternations in inspiratory oxygen fraction $\left(\mathrm{F}_{\mathrm{I}}, \mathrm{O}_{2}\right)$, during which a consistent alternation of instantaneous ventilation occurred.

infants, such as birthweight and gender, and the possible effects of variations in the gas concentrations measured during tests were investigated by adding terms into the analysis of variance. A p-value of less than 0.05 was considered to indicate statistical significance.

\section{Results}

\section{Subjects}

Eighteen infants completed 51 tests during polygraphically confirmed quiet sleep. Twelve tests in seven infants were unsuitable for further analysis as either the initial control or test period did not contain uninterrupted 20 breath sequences. Thirty nine test runs in 18 infants were analysed, an average of 2.2 test runs per infant, range 17 runs. Second control periods, recorded contiguously with the 2 min test period, were suitable for analysis in 20 runs in 12 infants. Satisfactory mass spectrometer signals of respired gas concentrations were obtained in 30 of the 39 runs.

\section{Respired gas concentrations}

During control periods breathing air, the mean (SEM) end-tidal oxygen concentration was $13.8(0.3) \%$ and mean end-tidal $\mathrm{CO}_{2} 5.1(0.1) \%$ for the group. During the two-breath alternations in $F_{\mathrm{I}, \mathrm{O}_{2}}$ the average end-tidal $\mathrm{O}_{2}$ increased from baseline values by $2.3 \%$ (95\% confidence interval $(95 \% \mathrm{CI}) 1.0$ to $3.5 \% ; \mathrm{p}=0.002)$ and the average end-tidal carbon dioxide concentration fell by $0.06(95 \%$ CI -0.02 to $-0.14 \%$; $\mathrm{p}=0.014)$.

Figure 3 shows the mean $( \pm 2 \mathrm{SEM})$ inspired and endtidal oxygen concentrations during baseline and test periods. The mean (SEM) inspired $\mathrm{O}_{2}$ alternated between 38.9 (1.0)\% and $2.9(0.5) \%$ during the test period with corresponding end-tidal $\mathrm{O}_{2}$ values of $20.9(0.9) \%$ and 11.0 $(0.3) \%$. Mean (SEM) end-tidal $\mathrm{CO}_{2}$ were $5.11(0.10) \%$ and $5.07(0.10) \%$ for high and low $F_{\mathrm{I}, \mathrm{O}_{2}}$ breaths, respectively $(\mathrm{p}=0.07)$.

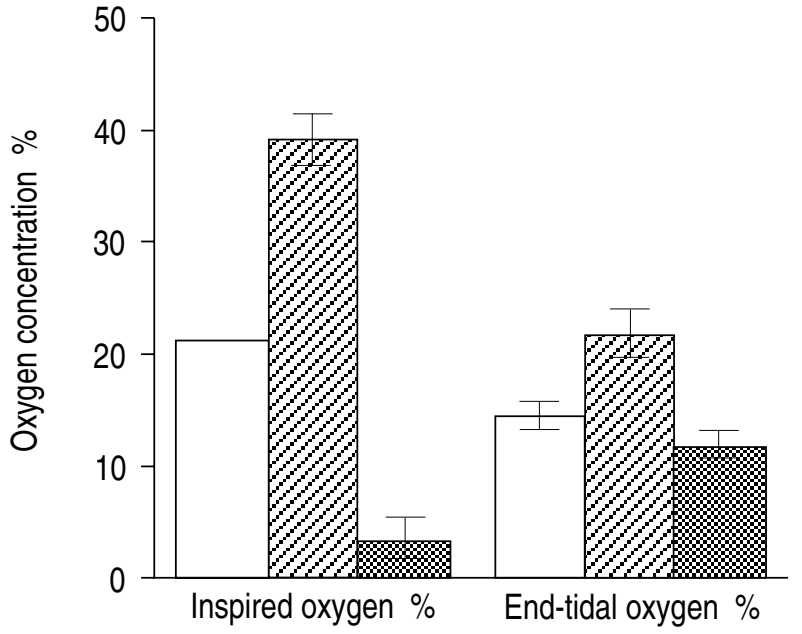

Fig. 3. - Inspired and end-tidal oxygen concentrations (mean \pm 2 sem) measured during baseline and periods of two-breath alternations in inspiratory oxygen fraction $\left(\mathrm{F}_{\mathrm{I}}, \mathrm{O}_{2}\right)$ in natural quiet sleep. $\square$ : base-

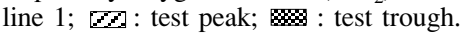

\section{Transcutaneous oxygen saturation}

Variation in the continuously monitored $\mathrm{Sa}_{\mathrm{a}} \mathrm{O}_{2}$ was observed during test periods; no value below $91 \%$ was recorded.

\section{Ventilation during test runs}

Mean values for indices of ventilation were computed for test periods and pre- and post-test control periods. Sequences of at least 20 breaths were utilized for analysis. No differences were observed during these periods for $V_{\mathrm{T}}, t \mathrm{\textrm {I }}, t \mathrm{\textrm {E }}, f_{\mathrm{R},} t \mathrm{\textrm {I }} / t \mathrm{tot}, V_{\mathrm{T}} / t \mathrm{\textrm {I }}$, or $V^{\prime} \mathrm{E}$.

\section{Test responses}

There was no relationship between percentage alternations in any index of ventilation during test periods and the corresponding initial baseline values. Results are, therefore, given as the percentage alternations during test periods.

Figure 4 shows the mean and two standard errors of the percentage alternations for each index of ventilation

Table 1. - Within and between infant variances of percentage alternations for each component of ventilation, taking into account differences in the number of observations among infants

\begin{tabular}{lcc}
\hline Indices & $\begin{array}{c}\text { Variance } \\
\text { within infants }\end{array}$ & $\begin{array}{c}\text { Variance } \\
\text { between infants }\end{array}$ \\
\hline$V \mathrm{~T}$ & 97 & 80 \\
$t \mathrm{I}$ & 44 & 19 \\
$t \mathrm{E}$ & 51 & 80 \\
$f_{\mathrm{R}}$ & 15 & 40 \\
$V \mathrm{~T} / t \mathrm{I}$ & 99 & 98 \\
$t \mathrm{I} / t$ tot & 64 & 68 \\
$V^{\prime} \mathrm{E}$ & 76 & 171 \\
\hline
\end{tabular}

$V \mathrm{~T}$ : tidal volume; $t \mathrm{I}$ : inspiratory time; $t \mathrm{E}$ : expiratory time; $f_{\mathrm{R}}$ : respiratory frequency; $V_{\mathrm{T}} / t \mathrm{I}$ : inspiratory flow; $t \mathrm{I} / t$ tot: inspiratory duty cycle; $V^{\prime} \mathrm{E}:$ minute ventilation. 


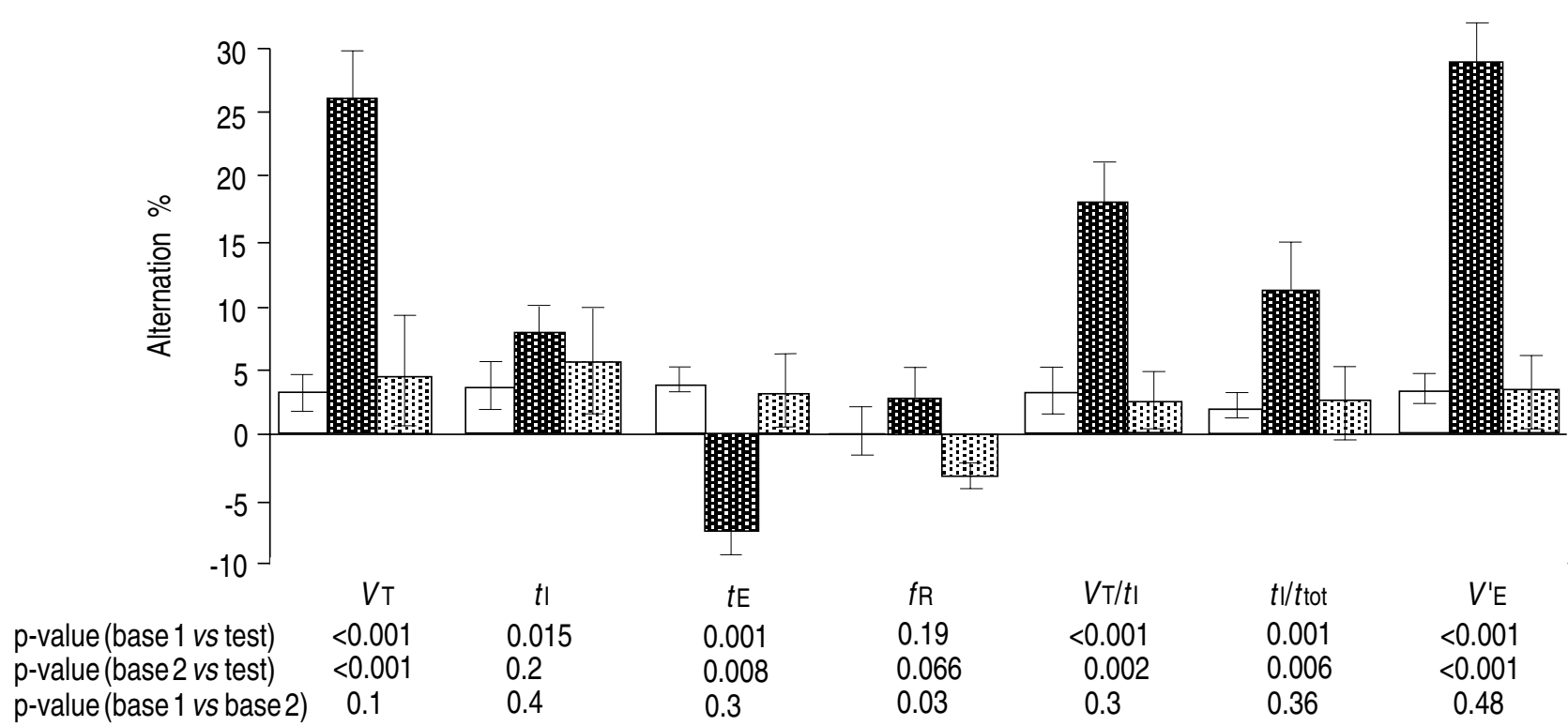

Fig. 4. - Percentage alternations (mean \pm 2 sem) measured during tests. All tests were made in natural quiet sleep. The data table gives the pvalues for paired t-tests between the different pairings of the three periods: $n=18$ infants with 39 tests for the first baseline and test periods; and 12 infants with 20 tests for the second baseline period. $\square$ : baseline 1; 8 ; : test; $5: 3$ : baseline 2 . $V$ T: tidal volume; $t$ : inspiratory time; $t \mathrm{E}$ : expiratory time; $f_{\mathrm{R}}$ : respiratory frequency; $V_{\mathrm{T}} / t \mathrm{I}$ : inspiratory flow; $t \mathrm{I} / t$ tot: inspiratory duty cycle; $V^{\prime} \mathrm{E}$ : instantaneous minute ventilation.

during baseline and test periods for all infants. For indices of ventilation other than $f_{\mathrm{R}}$ and $t \mathrm{I}$, the percentage alternations during the test period were significantly greater than in either baseline period. Pre- and post-test baseline observations were comparable for all indices except respiratory rate.

Table 1 gives the within and between infant variances of ventilatory responses, taking into account differences in the number of repeated tests among infants. The ratios of within/between variances differ considerably among the indices of ventilation.

The mean correlation coefficients ( $r$ values) from linear regression analysis of the cumulative ventilatory responses were utilized as an index of the consistency of the chemoresponse. Some variation was observed between the different components of respiration, with the mean $r$ values ranging from 0.74 for $t$ I to 0.96 for $V$ T.

\section{Potential confounding variables}

\section{Hering-Breuer reflex}

As the alternations in $V_{\mathrm{T}}$ were considerable (mean $26 \%$; range $4-58 \%$ ) an interaction between the chemoreflex induced and the Hering-Breuer reflex was investigated by plotting the $V_{\mathrm{T}}$ against the $t \mathrm{I}$ breath-by-breath for the breaths analysed in each test period [19]. The presence of a Hering-Breuer reflex interaction would be supported by an inverse relationship between $V_{\mathrm{T}}$ and $t \mathrm{I}$ above any given $V$ T. No such relationship was observed during any of the test periods.

\section{End-tidal oxygen concentration and ventilatory responses}

The order of the initial gas $\left(F_{\mathrm{I}, \mathrm{O}_{2}} 0.42\right.$ then 0.00 or $F_{\mathrm{I}, \mathrm{O}_{2}} 0.00$ then 0.42 ) during $F_{\mathrm{I}, \mathrm{O}_{2}}$ alternations did not affect the test responses. Variations in test responses were not accounted for by variation in the baseline end-tidal oxygen concentration or by the slight variation in the magnitude of alternations in end-tidal $\mathrm{O}_{2} \%$.

During the two-breath alternations in $\mathrm{F}_{\mathrm{I}} \mathrm{O}_{2}$ the mean end-tidal $\mathrm{O}_{2}$ concentrations increased from baseline by an average $2.3 \%$ (range $-1.1-6.3 \%$ ). Variation within but not between infants of alternations in $V_{\mathrm{T}}$ and instantaneous ventilation were inversely related to changes of the mean end-tidal $\mathrm{O}_{2} \%$ from baseline to test periods ( $\mathrm{p}=0.017$ and $\mathrm{p}=0.014$, respectively). Average end-tidal $\mathrm{O}_{2} \%$ differences had no effect on other test results.

\section{Birthweight, gender, rectal temperature and parental smoking}

Birthweight and gender had no effect on test results. The mean ambient temperature during tests was $22^{\circ} \mathrm{C}$ $\left(\mathrm{SD} 0.7^{\circ} \mathrm{C}\right)$. Rectal temperature, measured in 22 out of 39 tests in 11 infants was $36.5(0.2)^{\circ} \mathrm{C}$ and was unrelated to ventilatory responses observed.

The five infants with at least one smoking parent had lower alternations of $V_{\mathrm{T}} / t_{\mathrm{I}}($ mean $8 \%)$ when compared with those of the infants of 13 nonsmoking parents (mean $21 \%)(p=0.09)$. The two groups were comparable in respect of other test results.

\section{Discussion}

We have described a test of peripheral chemoreceptor responsiveness applicable in infancy. Minimal disturbance to the infant was ensured by avoiding contact with the face, and by the indirect measurement of ventilation by inductance plethysmography. These advantages were to some extent offset by the use of expensive monitoring equipment, to ensure that sleep state was adequately 
defined and that the concentrations of respired gases were recorded continuously.

\section{Regular breathing}

A regular breathing pattern is a critical requirement of the test described. Periodic breathing, isolated apnoeas and irregular breathing make comparisons of baseline and test periods for regular alternations in breathing difficult.

Some $49 \%$ of all test runs described were analysed without prior editing. In the remaining runs isolated sighs, breathing pauses and periods of irregular breathing were edited to permit analysis of uninterrupted regular breathing periods. This approach was consistent and any error introduced was not quantifiable.

\section{Arousal}

Trigeminal stimulation [9] was largely avoided as the face mask was not directly applied to the face; the effect of stimulation by the flow of gas was not assessed. Arousal of the infant during testing was uncommon, but occurred occasionally at the beginning of the initial baseline period and seemed to be related to the onset of gas flow at $120 \mathrm{~mL} \cdot \mathrm{s}^{-1}$. The supply of air to the face mask during control periods was uninterrupted. The possible effect of the solenoid valves was investigated in a single infant by comparing ventilation during control periods breathing air with that during periods when air was delivered via both lines supplying the face mask controlled by the solenoid valves during quiet sleep. No changes were observed in the ventilatory pattern. In the remaining infants, no evidence of arousal was observed during the operation of solenoid valves in the test periods. In future applications of the test, the use of alternating solenoid valves throughout control and test periods would control for any possible effect of the solenoid valves.

\section{Inductance plethysmography}

Tidal volume and its components were not measured directly. Inductance plethysmography provided an indirect measure of ventilation suitable for measuring changes on a breath-by-breath basis. It was assumed that the plethysmographic signal reflected changes in ventilation induced when applying the test to healthy infants. This assumption may not be appropriate for studies of sick or preterm infants, where chest wall stability is in question.

\section{Quantitation of the chemical stimulus}

The test stimulus was alternation of $F_{\mathrm{I}}, \mathrm{O}_{2}$ between 0.42 and 0.00 , chosen to obtain a mean $F_{\mathrm{I}} \mathrm{O}_{2}$ of 0.21 following initial modelling and in vivo test runs in healthy adult volunteers. No attempt was made to define "the best" alternating stimulus or the stimulus-response relationship for increasing alternations in $F_{\mathrm{I}, \mathrm{O}_{2}}$. Not surprisingly, the slight variation in the magnitude of the alternating stimulus delivered had no effect on the ventilatory responses observed. The two-breath alternations of $F_{\mathrm{I}}, \mathrm{O}_{2}$ gave second breath end-tidal oxygen concentrations of $21 \pm 1 \%$ and $11 \pm 0.3 \%$, respectively, a large stimulus of $10 \% \mathrm{O}_{2}$ delivered within a reasonably narrow range $(95 \% \mathrm{CI}$ $8-12 \%)$. Any unintentional variation in distance of the mask from the face during tests did not significantly affect the end-tidal oxygen concentrations recorded.

The increase in mean end-tidal $\mathrm{O}_{2} \%$ of some $2 \%$ above average baseline values during test periods was inversely correlated with percentage alternations of $V_{\mathrm{T}}$ and $V^{\prime} \mathrm{E}$. This confounding effect was found to account for approximately half of the within infant variation of response but not for differences between infants. Elimination of this increase in $F_{1}, \mathrm{O}_{2}$ would enhance the potential value of the test in future case/control studies involving groups of infants.

The within/between comparisons (table 1) gave results comparable with those observed using single-breath oxygen test method $[4,6]$. With the alternating breath test we observed a large coefficient of variation within a single day: results for alternations in tidal volume, inspiratory time and instantaneous ventilation were 39, 51 and $32 \%$, respectively, even after controlling for experimental conditions and relevant covariates. The test does not discriminate clearly between individuals but is useful in testing groups of infants of interest.

\section{Latency of response}

The interval between application of the stimulus and the ventilatory response ranged $2-8$ breaths $(1-4$ breath pairs). Lack of precise information on the stimulusresponse interval is a potential limitation of the test described, as the timing of the arrival of a chemical stimulus at the carotid body and the timing of the carotid body discharge reaching the brain could have a major influence on the ventilatory response induced $[20,21]$. This could be avoided in future studies by monitoring the beat-to-beat changes in $\mathrm{Sa}, \mathrm{O}_{2}$ at the earlobe with precise timing.

Although precise measurements of latency could not be determined, it was of the order of $9 \mathrm{~s}$. In our analysis, we discarded the first four breath pairs of the test period which, given a respiratory rate of 29 breaths $\cdot \mathrm{min}^{-1}$, accounts for $16.5 \mathrm{~s}$. It, therefore, seems likely that the infants would have been well-established in their pattern of ventilatory response at the point where we began to analyse the test periods.

\section{Analysis of measurements}

The means of all percentage alternations in ventilation and its indices for each test run are shown in figure 4. The consistency of these results is described by the correlation coefficients of the cumulative percentage alternations plotted against consecutive breath pairs. The greatest consistency was observed in alternations of tidal volume and instantaneous ventilation, correlation coefficient (r) values 0.96 and 0.95 , respectively. Inspiratory drive alternations had a mean $\mathrm{r}$ value of 0.89 , indicating a high 
degree of consistency of alternations during tests. For these three measures the differences between test and baseline periods were highly significant (all $\mathrm{p}<0.001$ ). Overall, the best discriminator of differences between infants was percentage alternation of instantaneous ventilation, between infant variance 171 ; within infant variance $76 ; \mathrm{r}=0.95$.

Previous studies have reported the responses of 2 day and 2 month old infants to alternations in $F_{\mathrm{I}, \mathrm{O}_{2}}[5,7]$, and have shown that in the human the resetting of the carotid body has occurred within $48 \mathrm{~h}$ of birth and shows no additional maturation up to the second month of postnatal life. The results in the present study are not directly comparable with those in the younger infants on account of the methodological differences described. The size of the stimulus in the present study was greater than in previous work; we observed an alternation of $28 \%$ in $V^{\prime} \mathrm{E}$ approximately five times greater than the response seen in the younger infants with a smaller stimulus $[5,7]$.

\section{Components of respiration}

Despite alternations in tidal volume of up to $58 \%$, interaction between the induced chemoreflex and the Hering-Breuer reflex was not observed. RABBETTE et al. [22] (1991) reported persistence of the Hering-Breuer reflex within the tidal breathing range until the second month of infancy. They compared the expiratory time after end-inspiratory airway occlusion with expiratory time during tidal breathing. The infants in the present study were a month older and our technique did not involve airway occlusion, which may account for the different findings.

Dividing the respiratory response into separate components allowed the nature of response to be investigated more fully. Minute ventilation $\left(V^{\prime} \mathrm{E}\right)$ expressed as the product of inspiratory flow $(V \mathrm{~T} / t \mathrm{I})$ and inspiratory duty cycle $(t \mathrm{I} / t$ tot $)[23]$ is thus divided into components independent $(V \mathrm{~T} / t \mathrm{I})$ and dependent $(t \mathrm{I} / t$ tot $)$ upon vagal influences [24]. The respiratory stimulus applied in the present study had its predominant effect on inspiratory flow, the ventilatory component that best reflects central inspiratory activity, providing further evidence that chemoresponses are not confounded by concurrent mechanical influences.

\section{Conclusion}

We have described a safe, relatively noninvasive method of measuring peripheral chemoresponsiveness to oxygen in infants, which is suitable for application in infancy, and have drawn attention to its possible limitations and scope for future development. It is potentially applicable in studies investigating the relationships between environmental factors that increase the risk for sudden infant death syndrome in infancy, such as maternal smoking, and peripheral chemoreceptor control mechanisms. Such studies might be relevant in investigating the possible relationship between respiratory control and sudden infant death syndrome in infancy.
Acknowledgements: The authors thank the Foundation for the Study of Infant Deaths for generous financial support and all the families who participated in this study. They would also particularly like to thank M.A. Hanson and P. Kumar for their generous support and encouragement, the loan of equipment and gift of software.

\section{References}

1. Weil JV, Byrne-Quinn E, Sodal IE, et al. Hypoxic ventilatory drive in normal man. J Clin Invest 1970; 49: 1061-1072.

2. Rigatto H, Brady JP, de la Torre Verduzco R. Chemoreceptor reflexes in preterm infants. 1 . The effect of gestational and postnatal age on the ventilatory response to inhalation of $100 \%$ and $15 \%$ oxygen. Pediatrics 1975; 55: 604-613.

3. Girard F, Lacaisse A, Dejours P. Le stimulus $\mathrm{O}_{2}$ ventilatoire a la period neonatale chez l'homme. J Physiol (Paris) 1960; 52: 108-110.

4. Parks YA, Beardsmore CS, MacFadyen UM, et al. The effect of a single breath of $100 \%$ oxygen on breathing at 1, 2 and 3 months of age. Am Rev Respir Dis 1991; 144: 141-145.

5. Williams BA, Smyth J, Boon AW, Hanson MA, Kumar $\mathrm{P}$, Blanco CE. Development of respiratory chemoreflexes in response to alternations of fractional inspired oxygen in the newborn infant. J Physiol (Lond) 1991; 442: 81-90.

6. Thomas DA, Swaminathan S, Beardsmore CS, et al. Comparison of peripheral chemoreceptor responses in monozygotic and dizygotic twin infants. Am Rev Respir Dis 1993; 148: 1605-1609.

7. Calder NA, Williams BA, Kumar P, Hanson MA. The respiratory response of healthy term infants to breathby-breath alternations in inspired oxygen at two postnatal ages. Pediatr Res 1994; 35: 321-324.

8. Calder NA, Williams BA, Smyth J, Boon AW, Kumar $\mathrm{P}$, Hanson MA. Absence of ventilatory responses to alternating breaths of mild hypoxia and air in infants who have had bronchopulmonary dysplasia: implications for the risk of sudden infant death. Pediatr Res 1994; 35 : 677-681.

9. Fleming PJ, Levine MR, Goncalves A. Changes in respiratory pattern resulting from the use of a face mask to record respiration in newborn infants. Pediatr Res 1982; 16: 1031-1034.

10. Yamamoto WS. Mathematical analysis of the time course of alveolar $\mathrm{CO}_{2}$. J Appl Physiol 1960; 15: 215-219.

11. Hornbein TF, Griffo ZJ, Roos A. Quantitation of chemoreceptor activity: interrelation of hypoxia and hypercapnia. J Neurophysiol 1960; 24: 561-568.

12. Fitzgerald RS, Leitner L-M, Liaubet MJ. Carotid chemoreceptor response to intermittent or sustained stimulation in the cat. Respir Physiol 1969; 6: 395-402.

13. Kumar P, Nye PCG, Torrance RW. Do oxygen tension variations contribute to the respiratory oscillations of chemoreceptor discharge in the cat? J Physiol (Lond) 1988; 395: 531-552.

14. Williams BA, Hanson MA. Role of the carotid chemoreceptor in the respiratory response of newborn lambs to alternate pairs of breaths of air and a hypoxic gas. $J$ Dev Physiol 1990; 13: 157-164.

15. Hanson MA, Kumar P, Williams BA. The effect of chronic hypoxia upon the development of respiratory chemoreflexes in the newborn kitten. J Physiol 1989; 411: 563-574. 
16. Anders T, Emde R, Parmelee A. A manual for standardized terminology and criteria for scoring of states of sleep and wakefulness in newborn infants. Los Angeles, UCLA Brain Information Service, Brain Research Institute Publications Office, 1971.

17. Sackner MA, Watson H, Belsito AS, et al. Calibration of respiratory inductive plethysmography during natural breathing. J Appl Physiol 1989; 66: 410-420.

18. Snedecor GW, Cochran WG. Statistical Methods. 6th edn. Chapter 10. IOWA, USA, Iowa State Press, 1967.

19. Clark FJ, von Euler C. On the regulation of depth and rate of breathing. J Physiol (Lond) 1972; 222: 267-295.

20. Nye PGC, Hanson MA, Torrance RW. The effect on breathing of abruptly stopping carotid body discharge. Respir Physiol 1981; 46: 309-326.

21. Ward SA, Cunningham DJC. The relation between hypoxia and $\mathrm{CO}_{2}$-induced reflex alternation of breathing in man. Respir Physiol 1977; 29: 363-378.

22. Rabbette PS, Costello KL, Stocks J. Persistence of the Hering-Breuer reflex beyond the neonatal period. J Appl Physiol 1991; 71: 474-480.

23. Milic-Emili J, Mazzarelli M, Derenne J-Ph, Whitelaw WA, Couture J. A new approach to study control of breathing. Clin Res 1985; 23: 646A.

24. Milic-Emili J, Grunstein MM. Drive and timing components of ventilation. Chest 1976; 70 (Suppl.): 131-133. 